\title{
Analisis Framing Detik.com dan Kompas.com Terhadap Pemberitaan Kualitas Udara Jakarta Terburuk di Dunia
}

\author{
Nishya Gavrila, Farid Rusdi \\ Nishyagavrila5@gmail.com farid@fikom.untar.ac.id \\ Fakultas Ilmu Komunikasi Universitas Tarumanagara
}

\begin{abstract}
On July 29, 2019, Jakarta's air quality was ranked first on the AirVisual.com website with the worst air quality statement in the world. According to AirVisual.com, Jakarta's Air Quality Index (AQI) stands at 188, which means the air quality in Jakarta is not healthy. On the same date, Detik.com and Kompas.com reported on the poor quality of Jakarta's air. The reason the author chose the latter is because based on the Alexa.com site, both news portals have the highest number of visitor readers in Indonesia. This study aims to determine and analyze Detik.com and Kompas.com in framing unhealthy air quality in Jakarta. The approach in this study uses a constructivist paradigm. by using Robert $N$. Entman's framing model that defines problems, diagnoses causes, makes moral judgment and recommendation treatment. From the results of this study, Detik.com further explained the response of Anies Baswedan regarding poor air quality in Jakarta, while on Kompas.com that poor air quality in Jakarta was a challenge for the government and the government could be convicted if it continued.
\end{abstract}

Keywords: detik.com, framing, jakarta's worst air quality in the world, kompas.com, news.

\section{Abstrak}

Pada tanggal 29 Juli 2019, kualitas udara Jakarta menempati peringkat pertama di situs AirVisual.com dengan pernyataan kualitas udara terburuk di dunia. Menurut AirVisual.com, Air Quality Index (AQI) Jakarta berada pada angka angka 188, yang artinya kualitas udara di Jakarta tidak sehat. Pada tanggal yang sama Detik.com dan Kompas.com memberitakan tentang buruknya kualitas udara Jakarta. Alasan penulis memilih kedua tersebut karena berdasarkan situs Alexa.com, kedua portal berita tersebut memiliki jumlah pengunjung pembaca terbanyak di Indonesia. Penelitian ini bertujuan untuk mengetahui dan menganalisis Detik.com dan Kompas.com dalam membingkai kualitas udara di Jakarta yang tidak sehat.Pendekatan dalam penelitian ini memakai paradigma konstruktivis, dengan menggunakan framing model Robert $\mathrm{N}$. Entman yakni define problems, diagnose cause, make moral judgement dan treatment recommendation. Dari hasil penelitian ini, Detik.com lebih menjelaskan tanggapan dari Anies Baswedan terkait buruknya kualitas udara Jakarta, sementara pada Kompas.com bahwa buruknya kualitas udara di Jakarta merupakan tantangan pemerintah dan pemerintah bisa dipidana jika terus dibiarkan.

Kata Kunci: detik.com, framing, kualitas udara jakarta terburuk di dunia, Kompas.com, Pemberitaan.

\section{Pendahuluan}

Seperti yang diketahui polusi sangat berbahaya bagi kesehatan, tidak hanya membahayakan orang dewasa saja namun membahayakan anak-anak juga. Belakangan ini polusi udara di Jakarta sedang menjadi sorotan. Pasalnya kualitas udara Jakarta dinyatakan kualitas udara terburuk di dunia, dengan berada pada urutan pertama yang diikuti oleh negara Dubai, United Arab Emirates, lalu Krasnoyarsk, 
Russia, Tehran, Iran dan Kuwait City, Kuwait yang dilansir dari situs AirVisual.com pada tanggal 29 Juli 2019 pukul 09.56 WIB.Melalui Kamus Besar Bahasa Indonesia (KBBI) polusi diartikan sebagai pengotoran berupa air, udara, dan sebagainya atau pencemaran. Kualitas udara yang memburuk disebabkan oleh saat musim kemarau menurut Badan Meteorologi, Klimatologi, dan Geofisika dengan singkatan (BMKG) yang merugikan sumber mutu udara yang memburuk disebabkan oleh saat musim kemarau. Hal ini bersumber karena ketiadaan hujan yang mampu mengurangi pengendapan atau pencucian terhadap polutan yang berada di udara oleh proses rain washing. Bisa juga disebabkan karena hari-hari yang sudah lama tidak terjadi hujan, berasal dari asap kendaraan bermotor atau mobil melalui knalpot, industri, pembakaran, atau faktor kecepatan angin yang rendah memungkinkan polusi udara tetap mengapung di udara pada suatu wilayah, dan menghasilkan peningkatan konsentrasi polutan dalam jumlah tinggi.

Terlebih lagi pada saat ini di ibu kota negara Indonesia yaitu Jakarta masih ada pekerjaan konstruksi penyelesaian jalur untuk LRT atau (Lintas Rel Terpadu), lalu pengerjaan trotoar dan kurangnya kesadaran masyarakat untuk mengandalkan dan menggunakan transportasi umum tetapi malah lebih mementingkan menggunakan kendaraan pribadi. Tentunya jika hal ini secara terus menerus dibiarkan akan menghasilkan debu partikel polutan yang tinggi.

Dilansir dari situs AirVisual, Senin pada tanggal 29 Juli 2019 pukul 06.10 WIB, Air Quality Index (AQI) Jakarta berjumlah 188, yang artinya kualitas udara di Jakarta tidak sehat. Pengertian AQI adalah indeks yang menggambarkan tingkat keparahan kualitas udara di suatu daerah. Berbagai portal berita di Indonesia langsung turut menyoroti akan fenomena buruknya kualitas udara di Jakarta dengan menempati posisi nomor satu di dunia. Salah satunya adalah Detik.com dan Kompas.com yang sama-sama memberitakan mengenai buruknya kualitas udara di Jakarta pada tanggal 29 Juli 2019. Berdasarkan situs Alexa.com Detik.com merupakan situs berita nomor satu yang paling banyak dikunjungi oleh pembaca, lalu yang kedua adalah Kompas.com, karena inilah penulis tertarik untuk menganalisis framing pemberitaan buruknya kualitas Jakarta di dunia.

Berdasarkan yang sudah dipaparkan oleh penulis diatas, latar belakang yang penulis sudah tulis di atas, maka itu rumusan masalahnya dapat dipaparkan sebagai berikut : "Bagaimana framing media online Detik.com dan Kompas.com dalam pemberitaan kualitas udara Jakarta terburuk di dunia?

Berangkat dari rumusan masalah yang sudah dipaparkan, adapun tujuan yang ingin disampaikan dari penelitian ini, sebagai berikut:

1.Untuk mengetahui bagaimana Detik.com dan Kompas.com sebagai portal berita online membingkai pemberitaan mengenai kualitas udara jakarta terburuk di dunia berdasarkan hasil situs Air Visual, pada hari Senin tanggal 29 Juli 2019 pukul 06.10 WIB, yang Air Quality Index (AQI) Jakarta dengan jumlah 188.

\section{Metode Penelitian}

Penelitian yang dipilih penulis yaitu memakai pendekatan penelitian deskriptif kualitatif. Penulis memilih penelitian deskriptif kualitatif karena pada penelitian ini penulis memperoleh data dari analisis artikel berita dan tidak dikaitkan dengan bentuk serta angka. 
Berdasarkan teori yang dipaparkan di atas penulis melakukan metode penelitian dengan menggunakan pendekatan paradigma konstruktivis. Lalu untuk analisis framing dalam penelitian ini penulis memilih framing versi Robert N. Entman. Konsep framing yang dipaparkan oleh Entman berfungsi untuk mengilustrasikan dua proses yakni seleksi serta menekankan aspek tersendiri dari realitas sebuah media. Framing menurut Robert berjumlah empat poin yakni pengenalan masalah, mencari pembawa suatu masalah, keputusan moral dan memfokuskan penyelesaian. Oleh karena itu penulis ingin melihat empat poin yang sudah dijelaskan, dalam suatu wacana melalui pemberitaan buruknya kualitas udara Jakarta di dunia pada Detik.com dan Kompas.com melalui framing Robert N. Entman.

Teknik pengumpulan data penulis adalah melalui data primer yaitu berdasarkan dari portal berita online itu sendiri, yakni lima artikel berita dari Detik.com, lima artikel berita dari Kompas.com mengenai pemberitaan kualitas udara Jakarta terburuk di dunia, lalu untuk data sekunder yang diperoleh merupakan studi pustaka mengenai analisis framing. Tiga tahapan dalam buku Memahami Penelitian Kualitatif (Sugiyono, 2016: 92) yang harus dikerjakan dalam menganalisis data penelitian kualitatif, yaitu memilah dan fokus pada hal yang penting, melakukan uraian yang singkat, dan mencari inti untuk ditarik kesimpulan.

\section{Hasil Temuan dan Diskusi}

Penulis memilih lima artikel berita dari masing-masing portal berita dari Detik.com dan Kompas.com dengan total sepuluh artikel yang telah dianalisis, jangka waktu yang penulis ambil dimulai dari tanggal 29 Juli 2019 sampai 31 Juli 2019. Berikut lima judul artikel yang penulis ambil dari Detik.com:

\begin{tabular}{llll}
\hline No. & Judul & \multicolumn{1}{l}{ Tanggal Terbit } \\
\hline 1. & $\begin{array}{l}\text { Data Airvisual Senin Pagi Udara Jakarta } \\
\text { Terburuk di Dunia. }\end{array}$ & Senin, 29 Juli 2019 \\
\hline 2. & $\begin{array}{l}\text { Udara Jakarta Terburuk di Dunia, ini Kata } \\
\text { Netizen. }\end{array}$ & Senin, 29 Juli 2019 \\
\hline 3. & $\begin{array}{l}\text { Polusi DKI Jakarta Tinggi, Anies Curiga karena } \\
\text { Aktivitas Kendaraan Berat di Tol. }\end{array}$ & Senin, 29 Juli 2019 \\
\hline 4. & $\begin{array}{l}\text { Anies Bicarakan Data Unik soal Polusi Jakarta } \\
\text { Bareng Pengelola Tol. }\end{array}$ & Selasa, 30 Juli 2019 \\
\hline 5. & $\begin{array}{l}\text { Risma: Makin Banyak Mobil, Perlu Banyak } \\
\text { Tanam Pohon untuk Serap Polusi. }\end{array}$ & Rabu, 31 Juli 2019 \\
\hline
\end{tabular}

Sedangkan untuk lima artikel berita yang penulis ambil dari Kompas.com adalah sebagai berikut:

\begin{tabular}{lll}
\hline No. & Judul & Tanggal Terbit \\
\hline 1. & $\begin{array}{l}\text { Data Airvisual, Kualitas Udara Jakarta Pagi Ini } \\
\text { Terburuk di Dunia. }\end{array}$ & Senin, 29 Juli 2019 \\
\hline 2. & $\begin{array}{l}\text { KPBB: Pemerintah Bisa Dipidana jika Abaikan } \\
\text { Polusi Udara Jakarta. }\end{array}$ & Senin, 29 Juli 2019 \\
\hline 3. & $\begin{array}{l}\text { Anies Curiga Polusi Udara Jakarta Disebabkan } \\
\text { Kendaraan Berat. }\end{array}$ & Senin, 29 Juli 2019 \\
\hline
\end{tabular}




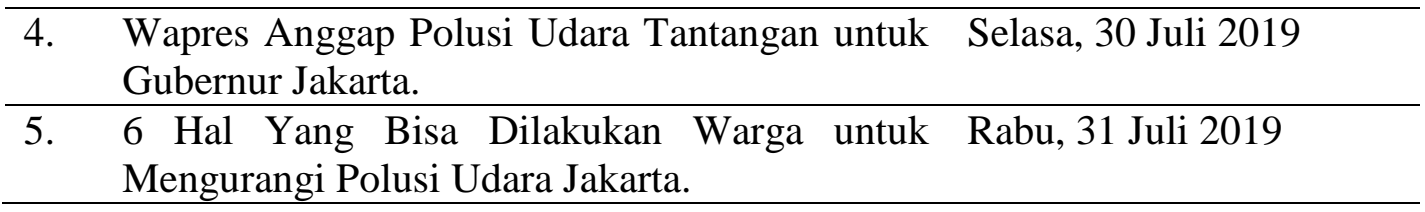

Berdasarkan hasil analisis yang sudah dilakukan oleh penulis dengan pemilihan lima artikel berita online secara keseluruhan, untuk elemen Problem Identification Detik.com menguraikannya selalu menggunakan situs AirVisual.com sebagai bukti mengenai buruknya kualitas udara Jakarta di dunia. Di sisi lain, Detik.com menyinggung tanggapan Anies Baswedan sebagai gubernur DKI Jakarta, dalam pemberitaan pertama Detik.com mengatakan belum adanya solusi dari Anies, sehingga dalam analisis yang penulis lakukan setelah pemberitaan pertama dimuat, Detik.com selalu memberitakan mengenai respon dan solusi yang diberikan oleh Anies tentang buruknya kualitas udara Jakarta di dunia. Sementara pada Kompas.com secara keseluruhan tetap menggunakan situs AirVisual.com sebagai data aktual terkait buruknya kualitas udara Jakarta, Kompas.com memang sempat tidak menyinggung tanggapan Anies pada pemberitaan pertama, namun pemberitaan berikutnya Kompas.com pun menyinggung Anies mengenai buruknya kualitas udara Jakarta di dunia , bahkan memberitakan jika Anies terus mengabaikannya bisa dipidana dan terkena pasal 112 undang-undang perlindungan dan pengelolaan lingkungan.

Dalam elemen Diagnose Cause, Detik.com secara keseluruhan dari 5 artikel berita yang telah penulis teliti membingkai kecurigaan Anies terhadap penyebab buruknya polusi udara Jakarta di dunia disebabkan oleh banyaknya volume kendaraan yang menghasilkan asap dan kemacetan sama halnya dengan Kompas.com membingkai sumber masalah dalam pemberitaan ini adalah adanya aktivitas dan kepadatan kendaraan-kendaraan berat namun pernyataan ini tidak hanya menggunakan tanggapan Anies disini Kompas.com menggunakan data dari KPBB (Komite Penghapusan Bensin Bertimbal) yang menunjukkan particulate matter (PM) 10 di DKI Jakarta paling banyak dari kendaraan bermotor, yaitu sebanyak 47 persen.

Pada elemen Make Moral Judgement disini Detik.com turut mewakilkan suara masyakat melalui kicauan netizen yang sumber beritanya diambil dari Twitter, Detik.com juga menghimbau masyarakat untuk menggunakan masker agar terlindungi dari buruknya kualitas udara di Jakarta, disini Detik.com melampirkan pernyataanpernyataan pemerintahan DKI Jakarta yaitu Anies, yang menghimbau agar mengurangi penggunaan kendaraan pribadi serta kendaraan berat untuk menguji pengecekan emisi yang dikeluarkan. Tak hanya pendapat Anies, Detik.com juga mensertakan solusi yang dikatakan Risma sebagai wali kota Surabaya tentang perlunya menanam pohon, sementara pada Kompas.com nilai moral yang disampaikan melalui analisis yang telah penulis lakukan hampir sama dengan Detik.com, bahwa pemberitaan Kompas.com selalu menggunakan tanggapan dari Anies, seperti kendaraan yang wajib memenuhi ambang batas emisi gas buang, lalu pemerintah yang siap mengatasi melalui 14 rancangan yang bertajuk "Jakarta Cleaner 2030", tak hanya itu Kompas.com turut melindungi masyarakat melalui pernyataan Ahmad Safrudin dan Ramly HI untuk mengeluarkan peringatan dini kepada masyarakat.

Lalu yang terakhir untuk treatment recommendation secara keseluruhan Detik.com menekankan perjumpaan yang akan dilakukan Anies untuk pengecekan batas emisi terhadap kendaraan-kendaraan yang melintasi tol JORR, serta menanam pohon untuk menyerap karbondioksida (CO2) menurut Risma (Wali Kota) Surabaya, sama halnya dengan Kompas.com secara menyeluruh dalam mengatasi masalah lebih 
menekankan untuk melakukan pengecekan ambang batas emisi gas yang dikeluarkan oleh kendaraan dan perusahaan otomotif yang menggunakan sistem emisi ramah lingkungan.

\section{Simpulan}

Setelah penulis melakukan analisis mengenai pembingkaian pemberitaan kualitas udara Jakarta terburuk di dunia pada Detik.com dan Kompas.com di bab IV, adapun kesimpulan yang peneliti peroleh adalah sebagai berikut :

\subsection{Framing Media Online Detik.com :}

Secara keseluruhan Detik.com membingkai pemberitaan kualitas udara Jakarta terburuk di dunia selalu membahas tanggapan dari Anies Baswedan sebagai Gubernur DKI Jakarta untuk memberi solusi mengatasi buruknya udara di Jakarta, penulis juga merangkum penyebab-penyebab buruknya kualitas udara di Jakarta versi Detik.com, yaitu disebabkan oleh adanya kendaraan berat yang melintasi wilayah jalan Tol JORR (Jakarta Outer Ring Road) dan pembangunan proyek. Pesan moral yang disampaikan oleh Detik.com adalah perlunya menanam pohon di wilayah Jakarta, menghimbau masyarakat untuk mengurangi penggunaan kendaraan pribadi, serta menguji pengecekan emisi gas yang dikeluarkan oleh kendaraan. Treatment Recommendation atau penyelesaian yang ditawarkan Detik.com untuk mengatasi buruknya kualitas udara di Jakarta adalah melakukan peraturan mengenai pengecekan emisi, bersama pengelola jalan tol JORR (Jakarta Outer Ring Road).

1.2. Framing Media Online Kompas.com :

Secara keseluruhan Kompas.com membingkai pemberitaan kualitas udara Jakarta terburuk di dunia tidak hanya menyinggung tanggapan dari Anies Baswedan, tetapi berbagai narasumber seperti Direktur Eksekutif Komite Penghapusan Bensin Bertimbal (KPBB) Ahmad Safrudin tentang perlunya memberikan arahan kepada masyarakat agar bisa menghindari udara kotor dan Wakil Presiden Jusuf Kalla. Kompas.com membingkai salah satu berita jika Anies tidak memberikan peringatan dini kepada masyarakat atas bahayanya kualitas udara Jakarta yang buruk akan dikenakan sanksi pidana namun pemberitaannya tidak memberi kesan untuk menjatuhkan, karena Kompas.com juga menayangkan artikel berita yang mengatakan bahwa dengan buruknya kualitas udara di Jakarta ini bukan hanya tantangan untuk Anies tetapi juga kepada masyarakat untuk sama-sama melakukan perubahan seperti mengurangi penggunaan kendaraan pribadi, urban farming / menanam kebun sendiri, dan tidak membakar sampah sembarangan.

\section{Ucapan Terima Kasih}

Penulis ucapkan terima kasih kepada Tuhan Yang Maha Esa dan Program Studi Ilmu Komunikasi, Universitas Tarumanagara sehingga penulis diberi kesempatan untuk meneliti "Analisis Framing Detik.com dan Kompas.com Terhadap Pemberitaan Kualitas Udara Jakarta Terburuk di Dunia".

\section{Daftar Pustaka}

Eriyanto. (2011). Analisis Framing: Konstruksi, Ideologi, dan Politik Media. Yogyakarta: LkiS 
Eva. (2019, Juli 29). Data AirVisual Senin Pagi: Udara Jakarta Terburuk di Dunia.

Diakses pada September 10, 2019, dari news.detik.com: https://news.detik.com/berita/d-4643051/data-airvisual-senin-pagi-udarajakarta-terburuk-di-dunia

Gunawan, Imam. (2014). Metode Penelitian Kualitatif:Teori dan Praktik. Jakarta:Bumi Aksara.

Kusumadewi, Etika Widya. (2016). Analisis Framing Pemberitaan Kisruh Partai Golkar Pasca Keputusan Menhukam Dalam Program Dialog Primetime News Metro TV Dan Kabar Petang TVOne. Diakses pada 9 September, 2019 dari Journal.Komunikasi,

https://journal.untar.ac.id/index.php/komunikasi/article/viewFile/68/152

Prastya, Narayana Mahendra. (2016). Kendala Struktural dan Kultural Praktek Keterbukaan Informasi Publik di Badan Non-Pemerintah: Studi Kasus PSSI. Diakses pada 9 September, 2019 dari Journal.Komunikasi, https://journal.untar.ac.id/index.php/komunikasi/article/view/170/829

Sugiyono. (2016). Memahami Penelitian Kualitatif. Bandung:PT Alfabet.

Thirafi, Hatif. (2019, Agustus 01). Data BMKG Menjelaskan Penurunan Kualitas Udara di Jakarta Biasa Terjadi Saat Musim Kemarau. Diakses pada September, 0, 2019, dari bmkg.go.id: https://www.bmkg.go.id/press-release/?p=databmkg-menjelaskan-penurunan-kualitas-udara-di-jakarta-biasa-terjadi-saatmusim-kemarau\&tag=press-release \&lang=ID

https://kbbi.web.id/polusi 